\title{
Validation of the HPV Impact Profile in Portuguese women with human papilloma virus
}

\section{B. Daiana Santos, Celia S. Moreira, Estela Vilhena, Emilia Carvalho \& M. Graça Pereira}

To cite this article: B. Daiana Santos, Celia S. Moreira, Estela Vilhena, Emilia Carvalho \& M. Graça Pereira (2019) Validation of the HPV Impact Profile in Portuguese women with human papilloma virus, Current Medical Research and Opinion, 35:7, 1275-1282, DOI: 10.1080/03007995.2019.1575193

To link to this article: https://doi.org/10.1080/03007995.2019.1575193

Accepted author version posted online: 28 Jan 2019.

Published online: 08 Mar 2019.

Submit your article to this journal $\pi$

山 Article views: 72

View Crossmark data ¿ 


\title{
Validation of the HPV Impact Profile in Portuguese women with human papilloma virus
}

\author{
B. Daiana Santos ${ }^{\mathrm{a}}$ (D) Celia S. Moreira ${ }^{\mathrm{b}}$ (D), Estela Vilhena ${ }^{\mathrm{c}}$ (D), Emilia Carvalho ${ }^{\mathrm{d}}$ (D) and M. Graça Pereira ${ }^{\mathrm{a}}$

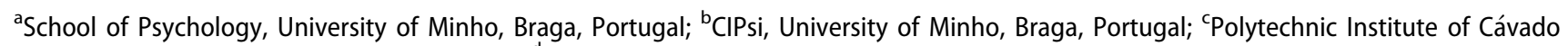 \\ and Ave, University of Porto, Porto, Portugal; ${ }^{d}$ School of Nursing of Ribeirão Preto, University of São Paulo, Ribeirão Preto, Brasil
}

\begin{abstract}
Objective: Human papilloma virus (HPV) is the world's most common causative agent in sexually transmitted viral infections; thus requiring clinical guidance, before and after treatment, to promote better quality of life in women diagnosed with HPV. The HPV Impact Profile (HIP) is a comprehensive instrument used to assess the psychosocial impact of HPV and related interventions in a wide range of domains. The main purpose of this study was to validate the HIP in Portuguese women, so that it can be used in this population, both in research and in clinical settings.

Methods: A sample of 178 Portuguese women infected with HPV were assessed with the following instruments: Index of Sexual Satisfaction, Hospital Anxiety and Depression Scale and HPV Impact Profile.

Results: The results of the confirmatory factor analysis showed some changes to the original model, which resulted in an adapted version with six domains, compared to the seven domains of the original model. The final model showed a good fit to the data. All Cronbach's alphas were higher than 0.79 indicating a high level of internal consistency of the subscales. As in the original HIP questionnaire, the exception was sexual impact, with a lower, but acceptable, Cronbach's alpha. Convergent and discriminant validities of the instrument were also assessed.

Conclusions: The Portuguese version of the HIP presents good psychometric properties, allowing its use in clinical trials as well as in clinical practice in order to evaluate quality of life in women with HPV.
\end{abstract}

\section{ARTICLE HISTORY}

Received 10 October 2018

Revised 8 January 2019

Accepted 24 January 2019

\section{KEYWORDS}

HPV; quality of life; validation; sexual satisfaction; morbidity

\section{Introduction}

The human papilloma virus (HPV) is a sexually transmitted virus that is lodged in mucous membranes or even on the skin, affecting both men and women. According to the American Centers for Disease Control and Prevention ${ }^{1}$, HPV is the world's most common causative agent in sexually transmitted viral infections. According to the WHO there are 2.784 million women 15 years old or over at risk of developing cervical cancer (CC). According to current estimates, every year, 527.624 women are diagnosed with this type of cancer, while 265.672 die from the disease ${ }^{2}$.

In Portugal, CC is considered the second most frequent gynecological malignant tumor in Portuguese women under 50. Moreover, between 2011 and 2015 this country showed a decrease in both incidence and mortality rate by $\mathrm{CC}^{3}$. The most common high-risk HPV types, 16 and 18, are associated with carcinoma, while type 6 and 11 are the most persistent in benign and premalignant lesions ${ }^{4}$. HPV represents a public health problem given the high prevalence of the infection leading to cancer, with the additional factor that the diagnosis carries a negative psychosocial impact on the patient's life ${ }^{5}$.
A qualitative study has revealed that an HPV diagnosis can cause two types of reaction in women: negative and positive. Negative impact concerns reactions such as shame or stigma, while the positive impact relates to reactions such as relief and happiness ${ }^{6}$. Also, studies show that both the clinical examinations and treatment cause suffering, anxiety and reduced quality of life $(\mathrm{QoL})^{7,8}$. Additionally, patients diagnosed with genital warts and diseases related to HPV have reported a negative impact on their psychosocial wellbeing and $\mathrm{QoL}^{9}$.

The diagnosis of a sexually transmitted infection (STI) and its treatment have a negative impact not only on women, but also on their marital relationship ${ }^{10}$. Factors such as fear of infection, and physical and psychosocial discomfort regarding the treatment were found to influence the sexual life of HPV-infected women and of their partners ${ }^{11}$. Upon receiving the diagnosis, many women cease wanting sexual intercourse while others reduce their activity ${ }^{11}$. The psychological, emotional and negative interpersonal aspects of having HPV are more relevant for sexual adjustment than the characteristics of the infection itself ${ }^{12}$. Additionally, women with an STI are not merely aware of these social stigmas: they internalize them, reporting reduced sexual satisfaction 
compared to men ${ }^{13}$. A study conducted at eleven hospitals including women diagnosed with HPV found a greater concern about sexuality and a negative impact in different stages of the infection, compared to the general population $^{14}$. On the other hand, sexually satisfied women, having positive sexual self-esteem and an active sexual life, experience reduced anxiety when confronted with the diagnosis/ treatment of $\mathrm{HPV}^{12}$. Results may be related to how much they are satisfied with their own relationship and with the communication within the relationship itself, as these factors moderate the impact of an HPV diagnosis related to sexual wellbeing and $\mathrm{QoL}^{12}$.

HPV infection is associated with anxiety, depression, fear of developing $\mathrm{CC}^{15,16}$ and worse QoL ${ }^{17,18}$. In addition, the everpresent concern associated with ongoing examinations, invasive and painful treatments, and consultations which increase in case of relapses, contribute even further to women's vulnerability regarding both emotional and sexual wellbeing ${ }^{19}$.

Psychosexual counseling is a key aspect to prevent further negative psychosexual results during the treatment of HPVrelated lesions ${ }^{20}$, in order to provide better clinical guidance, before and after treatment, and to promote a better QoL ${ }^{21}$.

The existing instruments that assess QoL in the presence of HPV are scarce. Thus, finding measures capable of assessing QoL associated with the health and the psychological impact of HPV is not only needed, but also relevant in order to design interventions that can meet the patients' needs within clinical practice ${ }^{22}$. Therefore, there is a need for instruments to assess the impact of this infection.

The HPV Impact Profile (HIP) was the first HPV-specific questionnaire able to assess, at once, a broader spectrum of HPV-related disease or conditions, including genital warts ${ }^{23}$. This instrument includes 29 items and aims at assessing the psychosocial impact of HPV in the following seven domains: 1 - worries and concerns; 2 - emotional impact; 3 - sexual impact; 4 - self-image; 5 - partner issues and transmission; 6 - interactions with doctors; 7 - control/life impact. Potential uses of this questionnaire include general research about HPV (e.g. study of evolution trends about the psychosocial impact of the HPV and analysis of predictors associated with higher psychosocial burden), as well as clinical settings, helping clinicians to identify impaired domains and, as such, to promote better QoL in this population.

The purpose of this study was to adapt the HIP ${ }^{23}$ to Portuguese women with HPV. This instrument has already been validated in Mandarin Chinese in order to avoid spelling and grammar mistakes, and wording errors, while preserving the original version and guaranteeing its cultural adequacy. It was applied as a pilot test ${ }^{24}$. However, the authors have not reported psychometric properties for this Chinese version. Therefore, to the best of our knowledge, this is the first HIP validation study in a foreign language.

\section{Methods}

\subsection{Participants}

The sample included 178 women with HPV who were receiving treatment in two major public hospitals in the Northern
Region of Portugal. Criteria for inclusion were: (i) adult women, with an HPV diagnosis; (ii) having a sexual partner. Exclusion criteria included being pregnant or having another STI.

\subsection{Instruments}

\subsubsection{HPV Impact Profile}

This questionnaire aims to assess the psychosocial impact of HPV infection ${ }^{23}$. It is made up of 29 items that are divided into seven domains: Worries/Concerns (e.g. "I am worried about having abnormal Pap test results"); Emotional Impact (e.g. "When I think about my recent gynecology exam or test results, I feel anxious"); Sexual Impact (e.g. "After my recent gynecology exam or test results, I am having less sex"); Self-Image (e.g. "When I think about my recent gynecology exam or test results, I feel my body is sexually attractive"); Partner/Transmission (e.g. "After my recent gynecology exam or test results, I am worried that having sex with my partner may give him/her and infection"); Interaction with Doctors (e.g. "I felt my recent gynecology procedures were embarrassing"); and Health Control/Life Impact (e.g. "After my recent gynecology exam or test results, I feel I can concentrate as well as usual on everyday matters"). Answers are provided on a Likert scale ranging from zero (Not at all) to ten (Extremely). The ranking of each domain is calculated through the sum of its items, divided by the number of items of the domain, multiplied by ten. The same formula is valid to calculate the total score. Higher scores indicate worse QoL.

\subsubsection{Index of Sexual Satisfaction}

This instrument is a 25-item unidimensional scale with the purpose of assessing the level of sexual satisfaction in a marital relationship (e.g. "Our sex life is very exciting" and "My partner seems to avoid sexual contact with me") ${ }^{25}$. Answers are provided on a Likert scale ranging from one (Never feel) to seven (Always feel). Higher results indicate higher levels of sexual dissatisfaction.

\subsubsection{Hospital Anxiety and Depression Scale}

The Hospital Anxiety and Depression Scale (HADS) ${ }^{26}$ assesses psychological morbidity in patients with physical pathologies in outpatient treatment. It is made up of 14 items, divided into two subscales: Anxiety (e.g. "I get a sort of frightened feeling as if something awful is about to happen") and Depression (e.g. "I get sudden feelings of panic"). Scores range from 0 to 21 for both subscales. Higher scores indicate higher levels of psychological distress.

\subsection{Procedure}

This study used a cross-sectional design. Data was collected in two hospitals in the Northern Region of Portugal, namely, Hospital of Braga and Hospital of Santa Luzia (ULSAM). The study was approved by the Portuguese Data Protection 
Authority (CNPD) and by each hospital's ethics committee. Patient identification was carried out by each patient's gynecologist who invited them if they fulfilled the inclusion criteria. In the diagnostic appointment, all women having a positive HPV result were informed by the gynecologist about the infection, including the specific HPV type. HPV type was then used to group patients into only two categories: low risk or high risk.

All patients were duly informed regarding the nature of the study itself, data confidentiality and voluntary participation, signing informed consent. All invited patients accepted to take part in this study. All data was collected in paper format and stored securely in locked file cabinets.

\subsection{Sample characteristics}

The sample included 178 women with HPV, ages ranging from 21 to $63(M=39, S D=9.85)$. Participants' education varied considerably, from 2 to 17 years. More specifically, $45.5 \%$ of the sample had at most nine school years, $36.5 \%$ attended a secondary school (10-12 years) and $18.0 \%$ had a university degree. The mean number of years of schooling is large (10.15) and so this sample is highly educated. Regarding marital status, $43.3 \%$ of participants were married. In this sample, $42.1 \%$ presented a high-risk HPV diagnosis. Table 1 presents the sample characterization.

\subsection{Data analysis}

Descriptive analyses were used to describe the sociodemographic and clinical characteristics of HPV women. A confirmatory factor analysis (CFA) was applied to the Portuguese version of the HIP $\mathrm{P}^{23}$. The HIP questionnaire was applied in a survey with 178 Portuguese women.

The CFA was performed using the structural equation modeling (SEM) technique, following the main recommendations presented by Brown ${ }^{27}$. The observed variables were analyzed as continuous data ${ }^{28}$. The robust ML estimator was used to compute non-normality robust standard errors and chi-square, through a scaling correction factor for the Satorra-Bentler method ${ }^{29}$. Reliability of the latent variables

Table 1. Sociodemographic characterization of women with HPV $(N=178)$.

\begin{tabular}{|c|c|c|c|c|}
\hline Continuous measure & Min & $\operatorname{Max}$ & Mean & SD \\
\hline Age & 21 & 63 & 39 & 9.85 \\
\hline Categorical measure & & & & $\%$ \\
\hline Basic education & & & & 45.5 \\
\hline Secondary education & & & & 36.5 \\
\hline Higher education & & & & 18 \\
\hline \multicolumn{5}{|l|}{ Civil status } \\
\hline Single & & & & 1.7 \\
\hline Married/common law union & & & & 57.9 \\
\hline Partner & & & & 40.4 \\
\hline \multicolumn{5}{|l|}{ HPV type } \\
\hline Type 6/11 low risk & & & & 57.9 \\
\hline Type $16 / 18$ high risk & & & & 42.1 \\
\hline Duration of treatment & & & & 24.2 \\
\hline Low risk, short HPV duration & & & & 33.7 \\
\hline Low risk, long HPV duration & & & & 17.4 \\
\hline High risk, short HPV duration & & & & 24.7 \\
\hline High risk, long HPV duration & & & & \\
\hline
\end{tabular}

was assessed using Cronbach's alpha and composite reliability $C^{30}$, with $C R>.7$ suggesting good factor reliability ${ }^{31}$. Convergent validity and discriminant validity were inspected using the average variance extracted ${ }^{30}$ and the Heterotrait-monotrait (HTMT) ratio of correlation criterion ${ }^{32}$. According to Hu and Bentler ${ }^{33}$ and $\mathrm{Kline}^{34}$, good model fit is indicated by a ratio chi-square over the number of degrees of freedom smaller than 3, CFI, TLI and RNI values "close to" .95 (or higher), RMSEA values "close to" .06 (or smaller), and SRMS values "close to" .08 (or smaller).

Statistical analyses were performed using the R statistical environment RStudio, version 3.4.3, ${ }^{35}$, through "lavaan" packages $^{36}$ and "semTools"

\subsection{Construct validity}

Mast et al. grouped the 29 items from the HIP ${ }^{23}$ into the following seven hypothesized domains (asterisks denote reverse scores): Domain 1 - Worries/Concerns (Items 7, 12, 13, 15, 16, 17, 18, 19, 20); Domain 2 - Emotional Impact (Items 2, 3, 5, 8, 14*); Domain 3 - Sexual Impact (Items 24, 25*); Domain 4 - Self-Image (Items $1 *, 10^{*}, 11,23$ ), Domain 5 - Partner/ Transmission (Items $9^{*}, 21,22$ ), Domain 6 - Interaction with Doctors (Items 27*, 28, 29); Domain 7 - Health Control/Life Impact (Items $\left.4^{*}, 6^{*}, 26\right)$. The adequacy of this item division to the sample of this study was explored. Extremely similar wordings were observed for items 21 and 22 in the Portuguese version and, thus, the corresponding residual correlation was included in the model.

As summarized in Table 2, applied to this study's sample, the model revealed poor reliability, validity problems and poor fitting to the data. Therefore, a new item division was developed based on both an exploratory factor analysis and a theoretical understanding of the literature review. This confluence between theory and statistics allowed the following six hypothesized domains to be obtained: Domain 1 Worries/Concerns (Items 3, 7, 12, 13, 15, 16, 17, 20), Domain 2 - Emotional Impact (Items 2, 5, 8, 26), Domain 3 - Sexual Impact (Items 9*, 24, 25*), Domain 4 - Future Treatment/ Transmission (Items 18, 19, 21, 22), Domain 5 - Positive Emotions (Items 1*, 4*,6* 10*, 14*, 27*), Domain 6 Negative Emotions (Items 11, 23, 28, 29).

A CFA was conducted to confirm the effectiveness of this factorial division. As before, the same residual correlation due to very similar wordings was added to the model. In general, this model presented good reliability and acceptable convergent validity (AVE values lower than the .5 threshold are indeed very close to this limit). Nevertheless, all the considered goodness-of-fit indices lay outside the recommended range, as summarized in Table 2.

The model fit was improved by removing all items with small factor loadings (less than .4). This procedure led to the elimination of six items out of 29 , namely items $7,11,12,13$, 20 and 26. Table 2 also presents the results of the CFA applied to the reduced model, with 23 indicators, which is depicted in Figure 1. 
Table 2. Results of the confirmatory factor analysis.

\begin{tabular}{|c|c|c|c|c|c|}
\hline \multirow[b]{2}{*}{ Model } & \multirow[b]{2}{*}{ Factor } & \multicolumn{3}{|c|}{ Validity/reliability measures } & \multirow[b]{2}{*}{ Fitting measures (scaled versions) } \\
\hline & & Alpha & CR & AVE & \\
\hline $\begin{array}{l}\text { Original HPV model } \\
\text { (Mast et } \text { al. }^{23} \text { ) }\end{array}$ & $\begin{array}{l}\text { Worries/Concerns 7, 12, 13, 15, 16, 17, 18, 19, } 20 \\
\text { Emotional Impact 2, 3, 5, 8, } 14 \\
\text { Sexual Impact 24, } 25 \\
\text { Self-Image 1, 10, 11, } 23 \\
\text { Partner/Transmission 9, 21, } 22 \\
\text { Interaction with Doctors 27, 28, } 29 \\
\text { Health Control/Life Impact4, 6, } 26 \\
\text { Total }\end{array}$ & $\begin{array}{l}0.88 \\
0.8 \\
0.74 \\
0.76 \\
0.66 \\
0.69 \\
0.66 \\
0.93\end{array}$ & $\begin{array}{l}0.88 \\
0.8 \\
0.74 \\
0.76 \\
0.54 \\
0.77 \\
0.66 \\
0.96\end{array}$ & $\begin{array}{l}0.57 \\
0.45 \\
0.59 \\
0.47 \\
0.33 \\
0.56 \\
0.44 \\
0.5\end{array}$ & $\begin{array}{l}\text { Chi-square }=907.51, d f=355 \\
\text { CFI }=.78 \\
\text { TLI }=.75 \\
\text { RNI }=.83 \\
\text { RMSEA }=.094 \\
\text { RMSEA upper } \\
90 \% \mathrm{Cl}=.100 \\
\text { SRMR }=.97\end{array}$ \\
\hline Initial model & $\begin{array}{l}\text { Worries/Concerns } 3,7,12,13,15,16,17,20 \\
\text { Emotional Impact } 2,5,8,26 \\
\text { Sexual Impact } 9^{*}, 24,25^{*} \\
\text { Future Treatment/Transmission 18, 19, 21, } 22 \\
\text { Positive Emotions } 1^{*}, 4^{*}, 6^{*}, 10^{*}, 14^{*}, 27^{*} \\
\text { Negative Emotions } 11,23,28,29 \\
\text { Total }\end{array}$ & $\begin{array}{l}0.82 \\
0.81 \\
0.69 \\
0.86 \\
0.83 \\
0.76 \\
0.93\end{array}$ & $\begin{array}{l}0.82 \\
0.81 \\
0.7 \\
0.85 \\
0.84 \\
0.79 \\
0.96\end{array}$ & $\begin{array}{l}0.5 \\
0.52 \\
0.48 \\
0.61 \\
0.48 \\
0.55 \\
0.52\end{array}$ & $\begin{array}{l}\text { Chi-square }=868.17 \\
d f=361 \\
\text { CFI }=.80 \\
\text { TLI }=.77 \\
\text { RNI }=.85 \\
\text { RMSEA }=.089 \\
\text { RMSEA upper } \\
90 \% \mathrm{Cl}=.095 \\
\text { SRMR }=.111\end{array}$ \\
\hline Final model (reduced model) & $\begin{array}{l}\text { Worries/Concerns } 3,15,16,17 \\
\text { Emotional Impact } 2,5,8 \\
\text { Sexual Impact } 9^{*}, 24,25^{*} \\
\text { Future Treatment/Transmission 18, 19, 21, } 22 \\
\text { Positive Emotions } 1^{*}, 4^{*}, 6^{*}, 10^{*}, 14^{*}, 27^{*} \\
\text { Negative Emotions } 23,28,29 \\
\text { Total }\end{array}$ & $\begin{array}{l}0.86 \\
0.79 \\
0.69 \\
0.86 \\
0.83 \\
0.83 \\
0.92\end{array}$ & $\begin{array}{l}0.87 \\
0.79 \\
0.71 \\
0.85 \\
0.84 \\
0.85 \\
0.96\end{array}$ & $\begin{array}{l}0.64 \\
0.55 \\
0.48 \\
0.61 \\
0.48 \\
0.71 \\
0.57\end{array}$ & $\begin{array}{l}\text { Chi-square }=296.27 \\
d f=214 \\
\mathrm{CFI}=.951 \\
\mathrm{TLI}=.943 \\
\mathrm{RNI}=.966 \\
\text { RMSEA }=.046 \\
\text { RMSEA upper } \\
90 \% \mathrm{Cl}=.056 \\
\text { SRMR }=.076\end{array}$ \\
\hline
\end{tabular}

Abbreviations. CR, Composite reliability; AVE, Average variance extracted; CFI, Comparative fit index; TLI, Tucker-Lewis Index; RNI, Relative noncentrality index; RMSEA, Root-mean-square error of approximation; SRMR, Standardized root mean square residual.

Asterisks denote reverse scores.

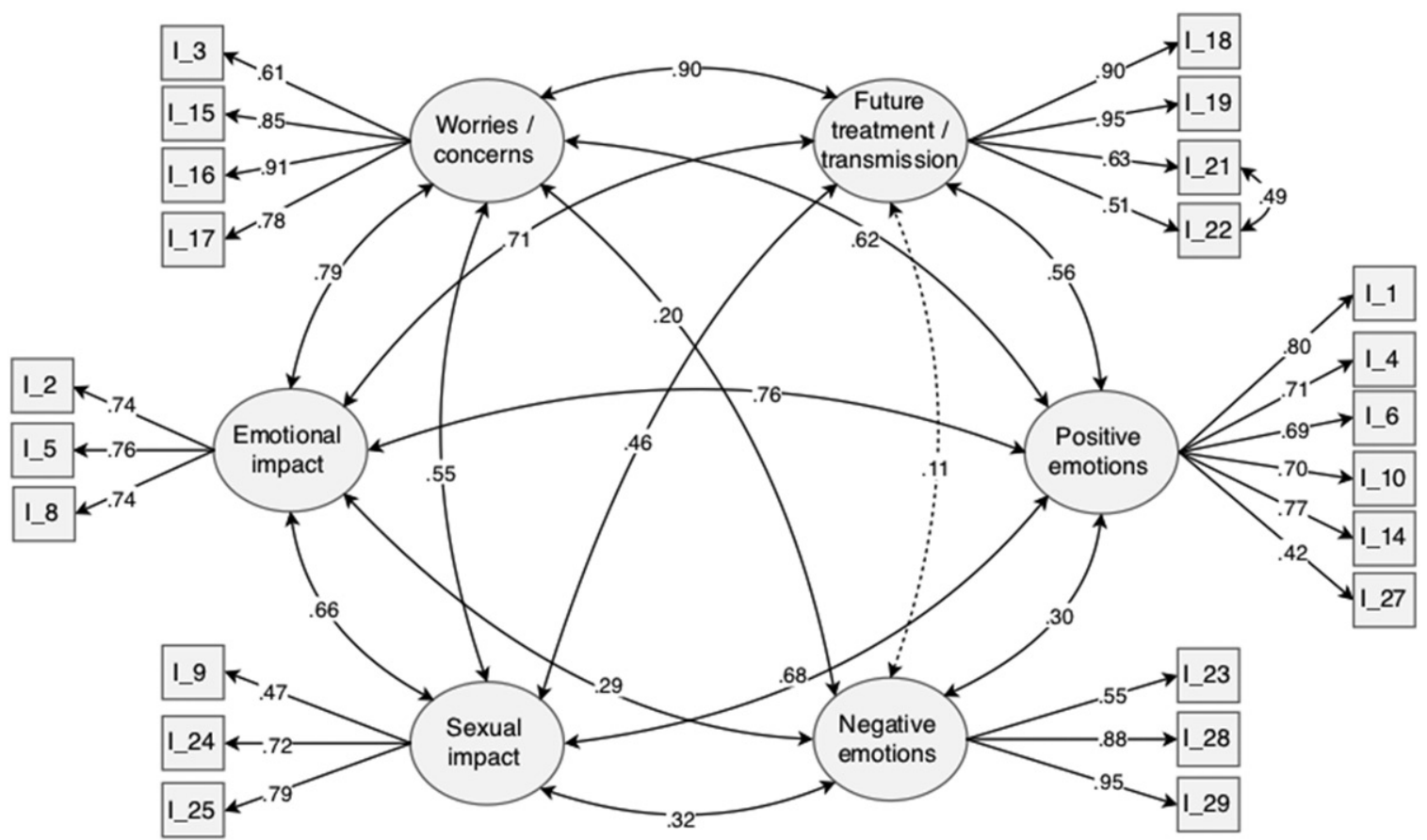

Figure 1. The final structural equation model for the HIP, fitting for Portuguese women diagnosed with HPV. Ellipses are the latent constructs (factors or scales) and rectangles are the indicators (items). All values are standardized parameter estimates. Solid lines represent significant relationships and the dashed line denotes a non-significant residual covariance. For clarity, errors of endogenous variables are not shown, but were included in the analysis.

\section{Results}

\subsection{Reliability}

As observed in Table 2, all six domains showed good construct reliability. Each domain exhibited acceptable Cronbach's alpha (from .69 to .86), good composite reliability and acceptable average variance extracted (only two values bordering below the .5 threshold). Goodness-of-fit measures are within the recommended range and thus good fit is achieved.

\subsection{Goodness-of-fit measures}

The results revealed a good adjustment of this model to the data: $\quad$ chi-square $=296.27 ; \quad \mathrm{df}=214 ; \quad \mathrm{CFI}=.951 ; \quad \mathrm{TLI}=.943$ 
Table 3. The HTMT ratio of correlations for the six-factor final model depicted in Figure 1, and the HADS and ISS scales.

\begin{tabular}{lllllllll}
\hline Factor & F1 & F2 & F3 & F4 & F5 & F6 & HADS & ISS \\
\hline F1 & & & & & & & & \\
F2 & .828 & & & & & & & \\
F3 & .618 & .713 & & & & & & \\
F4 & .849 & .692 & .507 & & & & & \\
F5 & .638 & .749 & .713 & .549 & & & & \\
F6 & .275 & .399 & .414 & .303 & .418 & & & \\
HADS & .390 & .667 & .538 & .362 & .599 & .331 & & \\
ISS & .195 & .334 & .772 & .175 & .435 & .347 & .564 & \\
\hline
\end{tabular}

Abbreviations. F1, Worries/Concerns; F2, Emotional Impact; F3, Sexual Impact F4, Future Treatment/Transmission; F5, Positive Emotions; F6, Negative Emotions; HADS, Hospital Anxiety and Depression Scale; ISS, Index of Sexual Satisfaction.

$\mathrm{RNI}=.966 ; \quad \mathrm{RMSEA}=.046 ; \quad \mathrm{RMSEA} \quad$ upper $\quad 90 \%$ $\mathrm{Cl}=.056 ; \mathrm{SRMR}=.076$.

\subsection{Discriminant validity}

The Heterotrait-monotrait (HTMT) ratio of correlations criterion $^{32}$ was used to establish the discriminant validity. This type of validity is used to guarantee that indicators of theoretically distinct constructs are not highly intercorrelated ${ }^{27}$. The HTMT matrix (Table 3 ) shows the discriminant validity of the model according to the HTMT criterion, as no entry exceeds the common prescribed cutoff of $0.85^{32}$. Comparing the HIP with the other two instruments (HADS and ISS), the discriminant validity was established, as before, through the HTMT matrix (Table 3), using the same argument.

\subsection{Convergent validity}

Convergent validity is indicated by evidence that different indicators of theoretically similar or overlapping constructs are strongly interrelated ${ }^{27}$. Convergent validity was established between the scales of HIP and psychological morbidity (HADS) and sexual satisfaction (ISS). Results are summarized in Table 4 and values greater than .5 were taken as evidence of convergent validity ${ }^{38,39}$. As expected, among all HIP domains, the strongest relationship of ISS was observed for Sexual Impact, and the strongest relationship of HADS was observed for Emotional Impact. ISS was also associated with the depreciation of Positive Emotions, and HADS was also related to both Sexual Impact and depreciation of Positive Emotions.

\subsection{Differences in quality of life according to HPV type and women's education level}

Quality of life showed differences according to the type of HPV $(t[176]=-5.161, p<.001)$. Women with high-risk HPV reported worse QoL when compared to those with low-risk HPV. However, there were no differences in QoL according to the women's level of education $(F[3,174]=.662, p=.576)$.

\section{Discussion}

The purpose of this study was the validation of the HIP 23 in a sample of Portuguese women diagnosed with HPV.
Table 4. Correlations between the HIP subscales and both the HADS and ISS measures.

\begin{tabular}{lllllll}
\hline Factor & F1 & F2 & F3 & F4 & F5 & F6 \\
\hline HADS & .389 & .661 & .533 & .371 & .597 & .357 \\
ISS & .161 & .324 & .756 & .096 & .429 & .362 \\
\hline
\end{tabular}

Abbreviations. F1, Worries/Concerns; F2, Emotional Impact; F3, Sexual Impact; F4, Future Treatment/Transmission; F5, Positive Emotions; F6, Negative Emotions; HADS, Hospital Anxiety and Depression Scale; ISS, Index of Sexual Satisfaction. Bold values are significant at $(p<.05)$.

The original scale includes 29 items and seven domains. Cronbach alphas were .90 for Worries/Concerns, .77 for Emotional Impact, .64 for Sexual Impact, .82 for Self-Image, .82 for Partner/Transmission, .69 for Interaction with Doctors and .71 for Health Control/Life Impact. In the present study, the CFA produced a final model with 23 items and six domains. Cronbach alphas were .86 for Worries/Concerns (with four items), 79 for Emotional Impact (with three items), .69 for Sexual Impact (with three items), .86 for Future Treatment/Transmission (with four items), .83 for Positive Emotions (with six items) and .83 for Negative Emotions (with three items). Therefore, when comparing the Cronbach alphas obtained in this study with the original version one finds they are relatively better, which demonstrates a high degree of internal consistency.

Compared with the original model, this study presents a first domain with the same name (Worries and Concerns), having removed six items (7, 12, 13, 18, 19 and 20), and included item 3, thus composing a final domain with four items. Items 7, 12, 13 and 20 were removed from the final model due to low factor loadings (below .4), granting a better model fit. In addition, particularly in this first domain, items 12 and 13 concerning worries about "genital warts" may not have been saturated because $81 \%$ of women claimed to have no lesions associated with HPV, and were therefore "not worried" about it. Nevertheless, undergoing pelvic examinations, Pap smear in particular, generates discomfort, fear and concern ${ }^{40}$.

In this study, the second domain maintains the name Emotional Impact, but left out item 3 (saturated in the first domain) and item 14 (saturated in the fifth domain). Consequently, this domain was left with three items. Flynn and collaborators ${ }^{41}$ report that women diagnosed with HPV experience a certain emotional impact upon diagnosis, often feeling anxiety and shame.

Regarding the Sexual Impact domain, this study added only item 9. Thus, the domain consisted of three items and maintained the same name. In general, items describe the sexual impact on women after the Pap smear, as well as a negative impact on marital relationships. Faced with a diagnosis and treatment of cervical dysplasia, women develop a sense of loss of control over their bodies, anxiety regarding their personal and genital health, compromising their body image and self-esteem, sexual life and marital adjustment, with an impact on sexual well-being ${ }^{17}$.

The fourth domain of this study comprises four items (18, 19, 21 and 22). It was named Future Treatment/Transmission due to item saturation and according to the semantics of the content within them, which deal with the fear of developing 
CC and concerns about transmitting the infection. In fact, HPV diagnosis, being significantly associated with anxiety, entails additional concerns for patients regarding sexual intercourse, decreasing sexual activity and fear of developing CC. In addition to these concerns, women feel guilt, fear and anguish when receiving a positive HPV result ${ }^{42,43}$.

The fifth domain refers to positive emotions (all items in this factor are reverse scored) and is made up of six items. As such, it was named Positive Emotions, since the semantics of the content focuses on women's positive feeling after the examination and feeling good about themselves. Thornton et al. $^{44}$ studied patients diagnosed with breast or gynecologic cancers and found that, in contrast to the great negativity observed, they were able to experience positive emotions which provided information on their own coping strategies.

The last domain of this study refers to negative emotions and consists of three items $(23,28$ and 29). Thus, this sixth domain was named Negative Emotions due to item saturation and semantics. The content addresses issues about women feeling sick, embarrassed and uncomfortable. An HPV diagnosis affects self-esteem and sexual satisfaction, generating frustration, embarrassment, annoyance and discomfort, influencing women's QoL ${ }^{20,42,43}$.

Despite the differences regarding the domains and composing items, the final model presents a good fit to the data.

With regard to convergent validity, this study used the Index of Sexual Satisfaction (ISS) instrument, per the prediction that QoL domains, namely Sexual Impact, were related to sexual satisfaction within the conjugal context. The internal consistency of this questionnaire is very high and, more precisely, Cronbach alpha in the original version was $.93, .95$ in the Portuguese version and .96 in this study. As expected, among all the HIP domains, ISS was strongly related to the Sexual Impact domain, together with a depreciation in Positive Emotions. The Hospital Anxiety and Depression Scale (HADS) was also used in this study and it evidenced convergent validity with the following HIP subscales: Emotional Impact, Sexual Impact and Positive Emotions. This convergence indicates that the HIP domains are strongly related to women's depression and anxiety. The literature suggests that the different stages of diagnosis and treatment of HPV infection may have different impacts on women and on couples ${ }^{45}$, with negative effects on sexual health and QoL throughout time ${ }^{46}$. Moreover, the literature also reports that an HPV positive result causes a negative impact on women's psychosocial and emotional lives, triggering feelings such as hopelessness, anger, fear, anxiety and depression ${ }^{47}$. Patients with lesions associated with HPV see their sexuality affected, thus experiencing a negative impact on their QoL ${ }^{9,48}$.

Discriminant validity was also demonstrated, showing that all HIP subscales were not highly correlated, either between themselves or with the ISS and HADS scales. This latter instrument showed high internal consistency: in the original version alphas were .85 for anxiety and .81 for depression; in the Portuguese version they were .76 and .81, respectively; and in this research, alphas were .91 and .88 , respectively. In this study, only the total scale was used. Among all the HIP domains, HADS was strongly related to the Emotional Impact domain. In addition to this association, HADS was related to both the Sexual Impact domain and a depreciation in positive emotions. When receiving an abnormal result in their Pap smear, women experience psychological distress, which causes a negative emotional impact, thus influencing their $\mathrm{QoL}^{49}$. In fact, women experience a strong emotional impact when receiving an HPV diagnosis ${ }^{50}$, with stigma and negative emotions ${ }^{51}$ such as anxiety, depression, anguish and concerns $^{16,52}$. This is because it precedes CC, regardless of a positive or negative result ${ }^{53}$. Furthermore, there is an increased negative psychological burden due to the infection's relapse rates, causing concern and anxiety in women ${ }^{54}$.

This study found that women with high-risk HPV (types 16/ 18) reported worse QoL than the low-risk ones. This result is in accordance with the literature that shows that when receiving a high-risk HPV diagnosis, patients experience greater suffering due to higher anxiety and fear of developing $\mathrm{CC}^{55}$. Additionally, STIs trigger conjugal, emotional, psychological and sexual consequences for women ${ }^{56}$. This study found no differences concerning participants' education level on QoL, probably because this sample is highly homogenous and highly educated. In the literature, the studies have mixed results. There are studies reporting that women with higher levels of education are more aware of the infection, which lessens their anxiety ${ }^{57,58}$ and improves their QoL. Conversely, the study by Daley and collaborators ${ }^{51}$ found that women with higher levels of education reported more negative emotions (anxiety/depression/fear). Hence, future studies should replicate these results in samples with women with lower education levels and assess the role of education on QoL.

This study had some underlying limitations: the sample was highly educated and there was a predomination of women with low-risk HPV. Consequently, future studies should include less educated women. It will also be important to evaluate the relationship between women's QoL and their partners' QoL, taking into account the type of HPV and the duration of the diagnosis.

In brief, the model outlined in Figure 1 with six latent constructs was applied to a sample of Portuguese women with HPV and showed goodness of fit, as well as good construct reliability and internal consistency. Convergent and discriminant validity were also established. These good psychometric properties give HIP the capacity to assess the psychosocial impact of HPV and related interventions in a wide range of domains in the Portuguese population. In particular, this instrument is of utmost importance in the HPV field, not only for future research studies, but also for clinical purposes. Indeed, clinicians may also apply HIP to identify QoL domains that need intervention and to promote better QoL in this population.

\section{Conclusions}

The results of this study show the importance of assessing psychosocial factors in women dealing with an HPV diagnosis. The HIP presents good psychometric qualities, showing 
good convergent validity, with significant associations with sexual satisfaction, along with good divergent validity regarding psychological morbidity (anxiety/depression). The confirmatory analysis revealed that the model presented good goodness-of-fit measures. The Portuguese version includes six domains (Worries/Concerns, Emotional Impact, Sexual Impact, Future Treatment/Transmission, Positive Emotions and Negative Emotions), being a relevant tool to be used in clinical trials, as well as in clinical practice, in terms of intervention, in order to assess the impact of HPV on women's QoL.

\section{Transparency}

\section{Declaration of funding}

This study was conducted at the Psychology Research Centre [UID/PSI/01662/2013], University of Minho, and supported by the Portuguese Foundation for Science and Technology and the Portuguese Ministry of Science, Technology and Higher Education through national funds and co-financed by FEDER through COMPETE2020 under the PT2020 Partnership Agreement [POCI-01-0145-FEDER-007653].

Author contributions: M.G.P. was responsible for the study design, data analysis and interpretation, manuscript review and editing; B.D.S. was responsible for manuscript preparation, data acquisition, data analysis and interpretation; E.C. contributed to study design, data analysis and manuscript review; C.S.M. and E.V. made substantial contributions to data analysis, data interpretation and manuscripts review.

\section{Declaration of financial/other relationships}

No potential conflict of interest was reported by the authors. CMRO peer reviewers on this manuscript have no relevant financial or other relationships to disclose.

\section{Acknowledgements}

The authors want to thank the patients and health professionals of Hospital de Braga and Hospital de Santa Luzia, in Portugal. All authors gave approval of the version to be published.

\section{ORCID}

B. Daiana Santos (ID http://orcid.org/0000-0001-5240-5219

Celia S. Moreira (D) http://orcid.org/0000-0001-5602-7171

Estela Vilhena (D) http://orcid.org/0000-0002-3063-5117

Emilia Carvalho iD http://orcid.org/0000-0003-0738-0539

M. Graça Pereira (iD http://orcid.org/0000-0001-7987-2562

\section{Data availability}

The data set used in this research is not available since this study is part of an ongoing PhD project.

\section{References}

[1] Centers for Disease Control and Prevention. Saving lives, protecting people. Atlanta (GA): EUA; 2015.
[2] World Health Organization (WHO). Human papillomavirus and related diseases [Internet]. 2017 [cited 2017 Sept 26]. Available from: http://www.hpvcentre.net/statistics/reports/XWX.pdf

[3] Direção Geral de Saúde. Programa Nacional Para as Doenças Oncológicas em números. Lisboa (Portugal): DGS; 2017.

[4] Scudellari M. HPV: sex, cancer and a virus. Nature. 2013;503: 330-332.

[5] Kami AK, Jacquelyn HK, Ryan, JH. The information management processes of women living with HPV. J Health Commun. 2014; 21(1):813-824.

[6] O'Connor M, Costello L, Murphy J, et al. 'I don't care whether it's HPV or ABC, I just want to know if I have cancer.' Factors influencing women's emotional responses to undergoing human papillomavirus testing in routine management in cervical screening: a qualitative study. BJOG. 2014;121(11):1421-1419.

[7] Furugori M, Asai-Sato M, Katayama K, et al. Short- and long-term complications and the impact on quality of life after cervical conization by harmonic scalpel. J Obstet Gynaecol Res. 2017;43(4): 749-757.

[8] O'Connor M, Costello L, Murphy J, et al.; Irish Cervical Screening Research Consortium (CERVIVA). Adverse psychological outcomes following colposcopy and related procedures: a systematic review. BJOG. 2015;123(1):24-38.

[9] Dominiak-Felden G, Cohet C, Atrux-Tallau S, et al. Impact of human papillomavirus-related genital diseases on quality of life and psychosocial wellbeing: results of an observational, healthrelated quality of life study in the UK. BMC Public Health. 2013;3: 1065.

[10] lżycki D, Woźniak K, lżycka N. Consequences of gynecological cancer in patients and their partners from the sexual and psychological perspective. Prz Menopauzalny. 2016;15:112-116.

[11] Jeng CJ, Lin H, Wang LR. Does treatment for cervical and vulvar dysplasia impact women's sexual health?. Taiwan J Obstet Gynecol. 2010;49(4):407-412.

[12] Foster LR, Byers ES. Predictors of the sexual well-being of individuals diagnosed with herpes and human papillomavirus. Arch Sex Behav. 2016;45(2):403-414.

[13] East L, Jackson D, O'Brien L, et al. Stigma and stereotypes: women and sexually transmitted infections. Collegian. 2012;19(1): 15-21.

[14] Wang SM, Shi JF, Kang DJ, et al. Impact of human papillomavirus-related lesions on quality of life: a multicenter hospital-based study of women in Mainland China. Int J Gynecol Cancer. 2011; 21(1):182-188.

[15] Drolet $M$, Brisson M, Maunsell E, et al. The impact of anogenital warts on health-related quality of life: a 6 month prospective study. Sex Transm Dis. 2011;38(10):949-956.

[16] Johnson CY, Sharp L, Cotton SC, et al. Human papillomavirus infection and anxiety: analyses in women with low grade cervical cytological abnormalities unaware of their infection status. PLoS One. 2011;6:1-6.

[17] Cendejas BR, Smith-McCune KK, Khan MJ. Does treatment for cervical and vulvar dysplasia impact women's sexual health? Am J Obstet Gynecol. 2015;212(3):291-297.

[18] Lin H, Jeng CJ, Wang LR. Psychological responses of women infected with cervical human papillomavirus: a qualitative study in Taiwan. Taiwan J Obstet Gynecol. 2011;50:154-158.

[19] Waller J, Marlow L, Wardle J. The association between knowledge of HPV and feelings of stigma, shame and anxiety. Sex Transm Infect. 2007;83(2):155-159.

[20] Graziottin A, Serafini A. HPV infection in women: psychosexual impact of genital warts and intraepithelial lesions. J Sex Med. 2009;6(3):633-645.

[21] Maxwell JH, Mehta V, Wang $\mathrm{H}$, et al. Quality of life in head and neck cancer patients: impact of HPV and primary treatment modality. Laryngoscope. 2014;24(7):1592-1597.

[22] Rao D, Gela N, Daley EM, et al. Developing a measure of health related quality of life for women with cervical dysplasia resulting from human papillomavirus infection. Int J STD AIDS. 2010;21(10): 697-701. 
[23] Mast TC, Zhu X, Demuro-Mercon C, et al. Development and psychometric properties of the HPV Impact Profile (HIP) to assess the psychosocial burden of HPV. Curr Med Res Opin. 2009;25(11): 2609-2619.

[24] Wang KL, Jeng CJ, Yang YC, et al. The psychological impact of illness among women experiencing human papillomavirus-related illness or screening interventions. J Psychosom Obstet Gynaecol. 2010;31(1):16-23.

[25] Hudson W. Index of Sexual Satisfaction. In: Davis C, Yarber W, Bauserman R, et al., editors. Handbook of sexuality-related measures. Thousand Oaks (CA): Sage; 1998. p. 512-513.

[26] Zigmond A, Snaith R. The Hospital Anxiety and Depression Scale. Acta Psychiatr Scand. 1983;67:361-370.

[27] Brown TA. Confirmatory factor analysis for applied research. New York (NY): Guilford Press; 2006.

[28] Rhemtulla M, Brosseau-Liard PÉ, Savalei V. When can categorical variables be treated as continuous? A comparison of robust continuous and categorical SEM estimation methods under suboptimal conditions. Psychol Methods. 2012;17(3):354-373.

[29] Oberski D. Lavaan.survey: an R package for complex survey analysis of structural equation models. J Stat Softw. 2014;57(1):1-27.

[30] Fornell C, Larcker DF. Evaluating structural equation models with unobservable variables and measurement errors. J Mark Res. 1981;18:39-50.

[31] Hair JF, Black WC, Babin BJ, et al. Multivariate data analysis. 7th ed. Upper Saddle River (NJ): Pearson Prentice Hall; 2010.

[32] Henseler J, Ringle CM, Sarstedt M. A new criterion for assessing discriminant validity in variance-based structural equation modeling. J Acad Marca Sci. 2015;43:115-135.

[33] Hu L, Bentler PM. Cutoff criteria for fit indexes in covariance structure analysis: conventional criteria versus new alternatives. Struct Equ Model. 1999;6:1-55.

[34] Kline RB. Principles and practice of structural equation modeling. New York (NY): Guildford; 2004.

[35] R Core Team. R: a language and environment for statistical computing [Internet]. Vienna (Austria): R Foundation for Statistical Computing; 2017. [cited 2018 October 10]. Available from: http:// www.R-project.org/

[36] Rosseel Y. Lavaan: an R package for structural equation modeling. J Stat Softw. 2012;48(2):1-36.

[37] Sem Tools Contributors. "semTools: useful tools for structural equation modeling". R package version 0.4-14 [Internet]. 2016. [cited 2018 October 10]. Available from: https://CRAN.R-project. org $/$ package $=$ semTools

[38] Cohen J. Statistical power analysis for the behavioral sciences. Hillsdale (NJ): Erlbaum; 1988.

[39] Ong AD, van Dulmen MHM. Series in positive psychology. Oxford handbook of methods in positive psychology. New York (NY): Oxford University Press; 2007.

[40] Cullen J, Schwartz MD, Lawrence WF, et al. Short-term impact of cancer prevention and screening activities on quality of life. J Clin Oncol. 2004;22(5):943-952.

[41] Flynn SM, Eisenlohr-Moul TA, Segerstrom SC, et al. "I have human papillomavirus": an analysis of illness narratives from the Experience Project. J Behav Med. 2017;40(5):814-820.
[42] Herzog T, Wright, DJ. The impact of cervical cancer on quality of life the components and means for management. Gynecol Oncol. 2008;107:572-577.

[43] Taberna M, Inglehart RC, Pickard RK, et al. Significant changes in sexual behavior after a diagnosis of human papillomavirus-positive and human papillomavirus-negative oral cancer. Cancer. 2017;123(7):1156-1165.

[44] Thornton LM, Levin AO, Dorfman CS, et al. Emotions and social relationships for breast and gynecologic patients: a qualitative study of coping with recurrence. Psychooncology. 2014;23(4): 382-389.

[45] Brandão T, Pedro J, Nunes N, et al. Marital adjustment in the context of female breast cancer: a systematic review. Psychooncology. 2017;26(12):2019-2029.

[46] Huffman LB, Hartenbach EM, Carter J, et al. Maintaining sexual health throughout gynecologic cancer survivorship: a comprehensive review and clinical guide. Gynecol Oncol. 2016;140(2): 359-368.

[47] Barnack-Tavlaris JL, Serpico JR, Ahluwalia M, et al. "I have human papillomavirus": an analysis of illness narratives from the Experience Project. Appl Nurs Res. 2016;30:137-141.

[48] Qi SZ, Wang SM, Shi JF, et al. Human papillomavirus-related psychosocial impact of patients with genital warts in China: a hospital-based cross-sectional study. BMC Public Health. 2014;14:739.

[49] Korfage IJ, Essink-Bot ML, Westenberg SM, et al. How distressing is referral to colposcopy in cervical cancer screening? A prospective quality of life study. Gynecol Oncol. 2014;132:142-148.

[50] Daley EM, Perrin KM, McDermott RJ, et al. The psychosocial burden of HPV: a mixed-method study of knowledge, attitudes and behaviors among HPV + women. J Health Psychol. 2010;15(2): 279-290.

[51] Daley EM, Vamos CA, Wheldon CW, et al. Negative emotions and stigma associated with a human papillomavirus test result: a comparison between human papillomavirus-positive men and women. J Health Psychol. 2015;20(8):1073-1082.

[52] McCaffery K, Waller J, Nazroo J, et al. Social and psychological impact of HPV testing in cervical screening: a qualitative study. Sex Transm Infect. 2006;82(2):169-174.

[53] Maldonado L, Wentzell E, Brown B, et al. Perceptions and experiences of human papillomavirus (HPV) infection and testing among low-income Mexican women. PLoS One. 2016;11(5):1-14.

[54] Mortensen GL, Larsen HK. The quality of life of patients with genital warts: a qualitative study. BMC Public Health. 2010;10:2-8.

[55] Kwan TT, Cheung AN, Lo SS, et al. Psychological burden of testing positive for high-risk human papillomavirus on women with atypical cervical cytology: a prospective study. Acta Obstet Gynecol Scand. 2011;90(5):445-445.

[56] Rosen N, Knãuper B, Di Dio P, et al. The impact of intolerance of uncertainty on anxiety after receiving an informational intervention about HPV: a randomised controlled study. Psychol Health. 2010;25(6):651-668.

[57] Rossi PG, Baldacchini F, Ronco G. The possible effects on socioeconomic inequalities of introducing HPV testing as primary test in cervical cancer screening programs. Front Oncol. 2014;4:20.

[58] Stark A, Gregoire L, Pilarski R, et al. Human papillomavirus, cervical cancer and women's knowledge. Cancer Detect Prev. 2008; 32(1):15-22. 